\title{
The Prevalence and Clinical Features of Skin Irritation Caused by Infection Prevention Measures During COVID-19 in the Mecca Region, Saudi Arabia
}

\author{
Ahmed ZahrAllayali (1D) \\ Amal Al-Doboke $\mathbb{D}^{2}$ \\ Rawan Alosaimy (iD ${ }^{2}$ \\ Renan Alabbasi $\mathbb{D D}^{2}$ \\ Sara Alharbi ${ }^{2}$ \\ Sarah Fageeh (ID $)^{2}$ \\ Shahad Altayyar $\mathbb{D D}^{2}$ \\ Ruqayya Azher ${ }^{3}$
}

'Dermatology, Department of Internal Medicine, College of Medicine, Umm AlQura University, Al-Abdia Main Campus, Makkah, Saudi Arabia; ${ }^{2}$ College of Medicine, Umm Al-Qura University, AlAbdia Main Campus, Makkah, Saudi Arabia; ${ }^{3}$ Department of Community Medicine, College of Medicine, Umm AlQura University, Al-Abdia Main Campus, Makkah, Saudi Arabia
Correspondence: Ahmed ZahrAllayali Dermatology, Department of Internal Medicine, College of Medicine, Umm AlQura University, Al-Abdia Main Campus, P.O Box 7I5, Makkah, Saudi Arabia $\mathrm{Tel}+966590041029$

Email ahmedz98@hotmail.com
Purpose: Due to the COVID-19 pandemic, recommendations to prevent infection suggest increasing the frequency of handwashing and disinfection; however, these measures can have negative implications on our skin. This study aims to evaluate whether these measures correlate with new-onset skin damage or can exacerbate hand eczema among the general population.

Materials and Methods: This was a descriptive, cross-sectional, survey-based study, including the general population of Mecca region, Saudi Arabia. To achieve the study's aim, an online questionnaire to the general population comprising 25 items was distributed via social media apps during the pandemic between October 23 and November 21, 2020. Data were automatically collected in Excel and entered into SPSS for analysis.

Results: A total of 783 participants were included in this study, of whom 695 (88.8\%) were female. A history of hand eczema was reported among 123 (15.7\%) participants, and 270 (34.5\%) had a history of atopy. During the COVID-19 pandemic, 86 (13.0\%) participants noticed new-onset skin irritation, while $81(31.3 \%)$ of the participants reported exacerbation of earlier hand allergic dermatitis. The most frequent symptoms were dryness and feeling of tightness. Additionally, most participants among both groups noticed that skin lesions appeared for less than 10 days. The frequent handwashing statistically increased following the onset of the pandemic $(\mathrm{p}=0.001)$, there is association between new-onset symptoms and more frequent handwashing, as well as the use of hand disinfectants, during the pandemic $(\mathrm{p}=0.001)$.

Conclusion: Our study suggests that the general population's skin was negatively affected by COVID-19 precautions, particularly those with a history of hand eczema. We recommend spreading awareness of skin protective modalities and the use of new infection prevention measures, such as regular skin moisturization for hand protection and possibly using less damaging skin disinfectants like ozonized water provided it is scientifically proven effective in disinfecting COVID-19 virus.

Keywords: COVID-19 pandemic, precautions, questionnaire, general population, skin, hand eczema

\section{Introduction}

Public health is currently struggling with the accelerated spread of the novel coronavirus disease (COVID-19) pandemic. ${ }^{1}$ COVID-19 affects the respiratory system and can cause pneumonia and acute respiratory distress syndrome, which are considered leading causes of death among infected individuals; therefore, social 
behavior has been significantly altered to prevent its spread. The World Health Organization (WHO) currently recommends different preventive measures, including social distancing, avoiding touching the face, wearing masks, wearing disposable gloves, and frequent handwashing using soap or alcohol-based disinfectants. ${ }^{2}$ While these measures are recommended to prevent transmission of COVID-19, they also may have negative implications on the skin.

Frequent handwashing (using soap and water for 40-60 seconds) has become the most important activity during the COVID-19 pandemic, following the WHO's recommendations; ${ }^{2}$ however, these measures might disturb the normal skin flora and natural protective skin barrier, leading to various skin diseases, most commonly irritant and allergic contact dermatitis. ${ }^{3}$

Internationally, a previous study ${ }^{4}$ conducted in China reported a $74.5 \%$ prevalence of hand eczema during COVID-19 among Health care workers, indicating that the COVID-19 pandemic may be associated with skin disorders. To our knowledge, no studies have been locally conducted regarding the prevalence of hand eczema among the Saudi general population during COVID-19. ${ }^{1}$

In this study, we hypothesized that skin damage among the general population might be observed with increased frequency due to increased hand hygiene measures. Thus, we aimed to evaluate whether the recommendations for frequent hand sanitation exacerbate hand eczema among the general population; additionally, we investigated whether this correlates with an onset of hand eczema and its associated symptoms.

\section{Materials and Methods}

\section{Study Design and Population}

This was a descriptive, cross-sectional, survey-based study, conducted via online survey distribution to the general population of Makkah. The study included all adults in the city of Makkah, with no exclusion criteria; 783 participants were included.

Regarding the sample size calculation, the minimum sample size required for this study was calculated by equation mentioned by Charan and Biswas in their study titled "How to Calculate Sample Size for Different Study Designs in Medical Research?". With assuming the prevalence of eczema will be around $37 \%$ as reported by study conducted in Najran, Saudi Arabia ${ }^{6}$ we would need
358 , based on confidence level of $95 \%$ and margin of error $5 \%$.

\section{Study Procedure}

An online questionnaire, designed in both English and Arabic (the native language of the participants) using Google forms, was electronically distributed between October 23 and November 21, 2020, via social media applications (twitter, WhatsApp, snapchat). The duration of data collection was 1 month.

\section{Study Instrument}

A modified questionnaire from previous published studies was used; $;^{3,4,7,8}$ validity was assessed before distribution. The supplementary questionnaire is available. It comprised 25 items, divided into five sections. Section one involved demographic data, including basic information regarding gender, age, marital status, nationality, smoking status, occupation, working hours, and time spent outside of the house. Section two involved the past medical history of the participants, including prior history of atopy and hand eczema. Section three involved the identification of new symptoms associated with hand eczema during the pandemic. Sections four and five included the frequency of handwashing, disinfection, and hand moisturization before and after the COVID-19 pandemic.

\section{Validation}

Item questions developed by the present researchers were revised/reviewed by three expert dermatologists for consistency and appropriateness. The questionnaire was found to be comprehensible; thus, no further modifications were required.

\section{Ethical Approval}

This study was ethically approved on October 4, 2020, by the Institutional Review Board (IRB) of Umm Al-Qura University (UQU) in Makkah, Saudi Arabia (Approval No. HAPO-02-K-012-2020-10-451).

\section{Data Analysis}

Data were collected in Excel and subsequently transferred into statistical package for the social science (SPSS) software, version 26 for statistical analyses. Descriptive statistics were used to summarize data and synthesize and report the variables. Description of the data also included proportions, frequencies, means, and standard deviations for continuous variables when appropriate. Chi-square test 
was used for categorical values (to determine the possible association between new-onset symptoms of skin damage and handwashing or using disinfectants), and McNemar's test was used for paired nominal data (to determine the association between handwashing, disinfection and moisturization, and rubber glove use, before and during the pandemic). The level of significance was 0.05 .

\section{Results}

\section{Characteristics of the Participants and Their History of Atopy-Related Diseases}

A total of 783 participants were included in this study; 695 $(88.8 \%)$ were female. Of the total participants, $402(51.3 \%)$ were aged between 20 and 30 years, and 149 (19.0\%) between 31 and 40 years. Regarding the current occupation of the participants, 260 (33.2\%) were students, while 205 (26.2\%) did not have work, regarding the time spent outside of the house, 497 (63.5\%) participants reported leaving home 1-2 times per week with exclusion for going to the work.

$270(34.5 \%)$ had one or more history of atopy; 136 (38.6\%) had eczema; and 151 (42.9\%) had allergic rhinitis. $503(64.2 \%)$ had one or more family member with a history of atopy, while $68(8.7 \%)$ did not know whether not their families had a history of atopy. Among those with a positive family history, 301 (37.8\%) had a family member with eczema, and 258 (32.4\%) had a family member with allergic rhinitis (Table 1).

\section{History of Hand Eczema and Associated Symptoms}

Table 2 demonstrates the history of hand eczema among participants; 123 (15.7\%) participants had a history of hand eczema. Regarding diagnosis, 105 (85.4\%) were diagnosed by a dermatologist, and 97 (78.9\%) were followed up by a dermatologist. Of the 123 participants, 104 (84.6\%) were prescribed medications for their hand eczema; however, $77(62.6 \%)$ reported only using these medications occasionally. Only 33 (26.8\%) participants noticed improvement in their hand eczema when they were away from work, whereas $57(46.3 \%)$ did not know for sure. The materials most reported to aggravate hand eczema were cleaning detergents in 88 (33.7\%), followed by soap in $76(29.1 \%)$. Table 2 demonstrates symptoms associated with hand eczema in participants with a past or current history of hand eczema. During the COVID-19 pandemic, 81 $(31.3 \%)$ participants with a history of hand eczema experienced worsening of symptoms and signs, and some exhibited more than one symptom, including 73 (30.4\%) dryness or tightness, followed by 65 (27.1\%) itching. The most reported skin lesions were erythema and desquamation $54(31.2 \%)$ and $52(30.1 \%)$, respectively. Regarding the duration of the lesions, $35(43.2 \%)$ cases appeared for less than 10 days, 17 (21.0\%) appeared for 11-20 days.

Table 3 demonstrates symptoms associated with hand eczema in people without a history of hand eczema. During the COVID-19 pandemic, 86 (13.0\%) participants noticed new skin damage. Among all participants, 104 $(30.7 \%)$ noticed dryness or tightness of their skin, and 79 $(23.3 \%)$ noticed scaling or fissures.

\section{Comparison Between Handwashing, Disinfection and Moisturization, and Rubber Glove Use Before and During the Pandemic}

Table 4 shows the results of the comparison between handwashing, disinfection and moisturization, and rubber glove use before the pandemic (before the announcement of first case of COVID-19 in the kingdom at 02/03/2020) ${ }^{9}$ and during the pandemic (after WHO announcement of COVID-19 pandemic at 11/03/2020). ${ }^{10}$ McNemar's test was used for paired nominal data; the result indicates a statistical difference between the daily frequency of handwashing with soap before and during pandemic ( $\mathrm{p}=0.001)$. During the pandemic, handwashing frequency increased compared with before the pandemic. Table 4 shows that only $2.6 \%$ of participants frequently washed their hands for more than 20 times per day before the pandemic; this frequency increased appreciably to $9.7 \%$ during the pandemic. Regarding hand disinfection, hand moisturizing, and rubber glove use, statistical differences were also observed before and during the pandemic $(\mathrm{p}=0.001)$; ultimately, participants used hand disinfectants less frequently before the pandemic than during pandemic.

\section{Association Between New-Onset Symptoms of Skin Damage with Handwashing and Using Disinfectants}

Table 5 shows the results of chi-square test conducted to determine an association between new-onset symptoms of skin damage and handwashing or using disinfectants. The results showed an association between new-onset symptoms and more frequent handwashing during the pandemic $(\mathrm{p}=0.001$ ). $33.7 \%$ of participants washed their hands 5-10 times per day had new-onset symptoms of skin damage, as 
Table I Demographic Characteristics of Participants N (\%)

\begin{tabular}{|c|c|c|}
\hline \multicolumn{2}{|l|}{ Characteristics } & \multirow{2}{*}{$\frac{\mathbf{N}(\%)}{88(11.2)}$} \\
\hline Gender & Male & \\
\hline & Female & $695(88.8)$ \\
\hline & $20-30$ & $402(51.3)$ \\
\hline \multirow[t]{5}{*}{ Age } & $31-40$ & $149(19.0)$ \\
\hline & $4 I-50$ & $102(13.0)$ \\
\hline & More than 50 & $73(9.3)$ \\
\hline & Less than 20 & $57(7.3)$ \\
\hline & Married & $352(45.0)$ \\
\hline \multirow[t]{2}{*}{ Marital Status } & Divorced or widow & $21(2.7)$ \\
\hline & Single & $410(52.4)$ \\
\hline \multirow[t]{2}{*}{ Nationality } & Saudi & $752(96.0)$ \\
\hline & Non-Saudi & $31(4.0)$ \\
\hline \multirow[t]{4}{*}{ Smoking } & Smoker & $92(11.7)$ \\
\hline & Non-smoker & $691(88.3)$ \\
\hline & Health care worker & $104(13.3)$ \\
\hline & Student & $260(33.2)$ \\
\hline \multirow[t]{5}{*}{ Current occupation } & Office worker & $66(8.2)$ \\
\hline & Teaching and education & III (I4.2) \\
\hline & Salesperson and customer service & $4(0.5)$ \\
\hline & Not working currently & $205(26.2)$ \\
\hline & Other & $33(4.2)$ \\
\hline \multirow[t]{3}{*}{ How often do you go out? (With exclusion to your job-if currently working) } & Rarely $(I-2)$ times per week & $497(63.5)$ \\
\hline & Sometimes (3-6) times per week & $204(26.1)$ \\
\hline & Usually $(>6)$ times per week & $82(10.5)$ \\
\hline \multirow[t]{2}{*}{ Do you have history of atopy-related diseases? } & Yes & $270(34.5)$ \\
\hline & No & $513(65.5)$ \\
\hline \multirow[t]{4}{*}{ If yes, please specify } & Eczema & $136(38.6)$ \\
\hline & Allergic rhinitis & $|5|(42.9)$ \\
\hline & Asthma & $47(13.4)$ \\
\hline & Others & $18(5.1)$ \\
\hline \multirow[t]{3}{*}{ Has anyone in your family been diagnosed with atopy-related diseases? } & Yes & $503(64.2)$ \\
\hline & No & $212(27.1)$ \\
\hline & Do not know & $68(8.7)$ \\
\hline
\end{tabular}

(Continued) 
Table I (Continued).

\begin{tabular}{|l|l|l|}
\hline \multicolumn{2}{|l|}{ Characteristics } & N (\%) \\
\hline If yes, please specify & Eczema & $301(37.8)$ \\
\cline { 2 - 3 } & Allergic rhinitis & $258(32.4)$ \\
\cline { 2 - 3 } & Asthma & $229(28.8)$ \\
\cline { 2 - 3 } & Others & $8(1.0)$ \\
\hline
\end{tabular}

well as $32.6 \%$ of participants who washed their hands with soap 11-20 times per day. In addition, the results showed an association between new-onset symptoms and more frequent hand disinfection during the pandemic $(\mathrm{p}=0.003)$.

\section{Discussion}

The recent COVID-19 pandemic has contributed to increased awareness of hand hygiene and handwashing. The Centre for Disease Control and Prevention recommends regular handwashing with soap and water to avoid virus transmission; as a result, the American Contact Dermatitis Society expects an increase in the incidence of both irritant and allergic contact hand dermatitis as healthcare staff and the general public concentrate on strict hand hygiene. ${ }^{8}$ This study, investigating the relationship between increased hand hygiene measures and new-onset skin damage during COVID-19, to our knowledge, this is one of the first study to be conducted in Saudi Arabia.

When comparing the overall frequency of handwashing with soap and using disinfectants, before and during the pandemic, our study showed a highly significant increase in both handwashing and disinfection following the pandemic $(p<0.001)$. Participants tended to wash their hands more than 10-20 times per day during the pandemic, similar to results reported among HCWs in a study conducted in Germany. ${ }^{3}$

Regarding the use of rubber gloves, the Centre for Disease Control and Prevention clarified that in most cases, wearing gloves is not mandatory for the general public during the COVID-19 pandemic; rather, they suggest that wearing gloves is only mandatory when someone is cleaning or caring for someone who is ill. Nevertheless, a significant increase in rubber glove use was noted in our study ( $<<0.001) ; 28.0 \%$ of participants reported using rubber gloves more than four times per week. However, using rubber gloves for a long duration, particularly without underlying moisturizer application, worsens and/or increases the risk of allergic and irritant contact dermatitis. $^{8}$

As shown in this study, frequent hand hygiene changes the nature of the skin, ranging from dryness to full-blown dermatitis. The study findings revealed a strong association between handwashing more than five times per day and hand eczema; $13.0 \%$ of participants noticed new-onset skin damage during the COVID19 pandemic, with dryness, scaling, and itching (30\%, $23 \%$, and $20 \%$, respectively) being the most commonly associated symptoms. Similarly, a previous observational study found that the most common clinical features of skin damage among first-line health care workers were dryness, tenderness, and itching $(70 \%, 56 \%$, and $52 \%$, respectively). ${ }^{11}$

Notably, $31.3 \%$ of participants with a current or prior history of hand eczema revealed worsening symptoms during the pandemic; dryness, itching, and erythema were the most commonly associated symptoms. High anxiety levels, exaggerated or irrational protection behaviors, and certain measures against COVID-19 may trigger or aggravate the emergence of various dermatological complaints; ${ }^{12}$ therefore, the use of moisturizers has been recommended to prevent hand eczema. ${ }^{8,13}$ Our study revealed a significant difference between the daily frequency of hand moisturizing before and during the pandemic; however, we cannot conclude from our study whether the use of hand moisturizers was for therapeutic intent after the development of hand eczema or for its prevention.

Hand eczema is a common disease and is regarded a public health concern. The estimated prevalence of hand eczema in our study was $15.7 \%$, and $85.4 \%$ of participants were diagnosed by a dermatologist. Comparatively, an earlier population-based study performed in Hail, Saudi Arabia, reported that the most common skin diseases were eczema, with an overall percentage of $37 \%$, and atopic dermatitis, 
Table 2 History of Hand Eczema Among Participants N (\%)

\begin{tabular}{|c|c|c|}
\hline \multicolumn{3}{|l|}{ History of Hand Eczema } \\
\hline \multirow[t]{2}{*}{ Ever reported hand eczema } & Yes & $\begin{array}{l}123 \\
(15.7)\end{array}$ \\
\hline & No & $\begin{array}{l}660 \\
(84.3)\end{array}$ \\
\hline \multirow[t]{2}{*}{ Have you been diagnosed by a dermatologist? } & Yes & $\begin{array}{l}105 \\
(85.4)\end{array}$ \\
\hline & No & $18(\mid 4.6)$ \\
\hline \multirow[t]{2}{*}{ Are you been followed up by a dermatologist? } & Yes & $\begin{array}{l}97 \\
(78.9)\end{array}$ \\
\hline & No & $\begin{array}{l}26 \\
(21.1)\end{array}$ \\
\hline \multirow[t]{2}{*}{ Have you been prescribed medication for your hand eczema? } & Yes & $\begin{array}{l}104 \\
(84.6)\end{array}$ \\
\hline & No & $\begin{array}{l}19 \\
(15.4)\end{array}$ \\
\hline \multirow[t]{3}{*}{ Are you using these medications? } & Regularly & $\begin{array}{l}21 \\
(17.1)\end{array}$ \\
\hline & Not using them & $\begin{array}{l}25 \\
(20.3)\end{array}$ \\
\hline & Occasionally & $\begin{array}{l}77 \\
(62.6)\end{array}$ \\
\hline \multirow[t]{3}{*}{ Does your hand eczema improve when you are away from work? } & Yes & $\begin{array}{l}33 \\
(26.8)\end{array}$ \\
\hline & No & $\begin{array}{l}33 \\
(26.8)\end{array}$ \\
\hline & Do not know & $\begin{array}{l}57 \\
(46.3)\end{array}$ \\
\hline \multirow[t]{7}{*}{ Materials reported to aggravate your existing hand eczema } & Cleaning detergents chemicals & $\begin{array}{l}88 \\
(33.7)\end{array}$ \\
\hline & soap & $\begin{array}{l}76 \\
(29.1)\end{array}$ \\
\hline & $\begin{array}{l}\text { Oils, industrial lubricants, foods, and } \\
\text { plants }\end{array}$ & $\begin{array}{l}27 \\
(10.3)\end{array}$ \\
\hline & Solvents and paint & $25(9.6)$ \\
\hline & Water & $22(8.4)$ \\
\hline & Animals & $15(5.7)$ \\
\hline & Other & $8(3.1)$ \\
\hline
\end{tabular}

(Continued) 
Table 2 (Continued).

\begin{tabular}{|c|c|c|}
\hline \multicolumn{3}{|l|}{ History of Hand Eczema } \\
\hline \multicolumn{3}{|c|}{$\begin{array}{l}\text { Worsening of symptoms associated with hand eczema during the pandemic } \mathbf{N}(\%) \text { (For people with past or current history of } \\
\text { hand eczema) }\end{array}$} \\
\hline \multirow[t]{2}{*}{$\begin{array}{l}\text { If you had hand eczema before: After the onset of the pandemic, did you notice worsening of } \\
\text { your symptoms? }\end{array}$} & Yes & $\begin{array}{l}81 \\
(31.3)\end{array}$ \\
\hline & No & $\begin{array}{l}178 \\
(68.7)\end{array}$ \\
\hline \multirow[t]{6}{*}{ What symptoms/signs did you notice that got worse? } & Dryness or tightness & $\begin{array}{l}73 \\
(30.4)\end{array}$ \\
\hline & Itching & $\begin{array}{l}65 \\
(27.1)\end{array}$ \\
\hline & Scaling or fissures & $\begin{array}{l}39 \\
(16.3)\end{array}$ \\
\hline & Erythema & $\begin{array}{l}45 \\
(18.8)\end{array}$ \\
\hline & Burning or pain & $14(5.8)$ \\
\hline & Tenderness & $4(1.7)$ \\
\hline \multirow[t]{7}{*}{ Please choose the listed skin lesion which best match your skin damage } & Desquamation & $\begin{array}{l}52 \\
(30.1)\end{array}$ \\
\hline & Fissure & $\begin{array}{l}32 \\
(18.5)\end{array}$ \\
\hline & Erythema & $\begin{array}{l}54 \\
(31.2)\end{array}$ \\
\hline & Erosion or Ulcer & $\begin{array}{l}20 \\
(11.6)\end{array}$ \\
\hline & Papule & II (6.4) \\
\hline & Maceration & $3(1.7)$ \\
\hline & Other & $\mathrm{I}(0.6)$ \\
\hline
\end{tabular}

comprising $12 \%$ of eczema cases. ${ }^{14}$ A review of studies regarding the prevalence and incidence of hand eczema among the general population of most of Europe showed that the estimated prevalence within a year ranged from $6.5 \%$ to $17.5 \% ;^{13}$ a similar overall prevalence was identified in our study.

Previous studies performed in China revealed that frequent hand hygiene is a risk factor for hand eczema; ${ }^{11}$ while in most hand eczema research, handwashing has been by far the most significant risk factor for the development of hand eczema. ${ }^{13}$
In our study, $29.1 \%$ of participants with eczema revealed that soap would aggravate their hand eczema, while $33.7 \%$ reported that cleaning detergents worsen their condition. An observational study including the pediatric population without a history of hand eczema was performed in Denmark during the COVID-19 pandemic; a strong correlation was observed between the frequency of handwashing and hand eczema. The study reported that $42.4 \%$ of participants suffered from irritant contact dermatitis during the COVID-19 pandemic, which was more obvious with handwashing using soap than 
Table 3 New-Onset Symptoms Associated with Hand Eczema During the Pandemic N (\%) (for People with No History of Hand Eczema)

\begin{tabular}{|c|c|c|}
\hline \multirow{3}{*}{$\begin{array}{l}\text { After the onset of the pandemic, have you noticed newly developed obvious skin } \\
\text { damage? }\end{array}$} & Yes & $86(13.0)$ \\
\hline & No & $524(79.4)$ \\
\hline & I am not sure & $50(7.6)$ \\
\hline \multirow[t]{6}{*}{ What symptoms/signs did you develop? } & Dryness or tightness & $104(30.7)$ \\
\hline & Scaling or fissures & $79(23.3)$ \\
\hline & Itching & $71(20.9)$ \\
\hline & Erythema & $65(19.2)$ \\
\hline & Tenderness & $13(3.8)$ \\
\hline & Burning or pain & $7(2.1)$ \\
\hline \multirow[t]{7}{*}{ Please choose the listed skin lesion which best match your skin damage: } & Burning or pain & $7(3.0)$ \\
\hline & Desquamation & $87(36.7)$ \\
\hline & Erosion or Ulcer & $19(8.0)$ \\
\hline & Erythema & $70(29.5)$ \\
\hline & Fissure & $36(15.2)$ \\
\hline & Papule & $12(5.1)$ \\
\hline & Other & $6(2.5)$ \\
\hline
\end{tabular}

using alcohol-based disinfectants. ${ }^{15}$ Overall, the findings of their study were similar to our own.

\section{Limitations, Strengths, and Recommendations}

The design of the current study is subject to limitations, as with most research. Our study was cross-sectional, and with participants asked to complete an online questionnaire, a self-administered questionnaire through an online platform could be biased depending upon the lack of some people access to the internet, it may lead to demographic bias by recruiting a younger, more internet active population. Therefore, people who aged more than 50 and less than 20 are present a lower percentage in the study. In terms of sex, the two groups were not equal; more than $70 \%$ of participants were female however, no distinction was made between them in our study. Therefore, both age and sex may affect the external generalizability. Regarding self-reported hand eczema, previous studies have shown that self-reported hand eczema is valid. ${ }^{16}$ Additionally, as the sample was restricted to a limited region of Saudi Arabia, the study's result may not be generalizable.
Despite that some studies showed that females seemed to have a higher level of awareness relative to males on hand washing and personal safety, as well as they have healthier behaviors. $^{17}$

\section{Conclusions}

In conclusion, our study suggests that the general population's skin is affected by COVID-19 precautionary measures. It is reported that nearly half of participants experienced the onset of skin damage, particularly those with a history of hand eczema. Furthermore, a significant association between new-onset symptoms and more frequent hand washing during the pandemic was detected Therefore, we recommend spreading awareness of skin protective modalities and the use of new infection prevention measures, such as regular skin moisturization for hand protection and possibly using less damaging skin disinfectants like ozonized water for hand disinfection as it has been shown to be more effective and skin-friendly than alcohol for eradicating E. Coli, although further research is needed to see whether it can be used effectively against viruses such as COVID-19. ${ }^{18}$ 
Table 4 Comparison Between Handwashing, Disinfection and Moisturization, and Rubber Glove Use Before and During Pandemic

\begin{tabular}{|c|c|c|c|c|}
\hline \multicolumn{2}{|c|}{$\begin{array}{l}\text { Daily Frequency of Handwashing, Disinfection and Moisturization, and Rubber } \\
\text { Glove }\end{array}$} & \multirow{2}{*}{$\begin{array}{l}\text { Before COVID-I9 } \\
44.6 \%\end{array}$} & \multirow{2}{*}{$\begin{array}{l}\text { During COVID-I9 } \\
20.3 \%\end{array}$} & \multirow{2}{*}{$\begin{array}{l}\text { Sig* } \\
0.001\end{array}$} \\
\hline Daily frequency of handwashing with soap & $<5$ times & & & \\
\hline & $5-10$ times & $43.9 \%$ & $45.3 \%$ & \\
\hline & 10-20 times & $8.9 \%$ & $24.6 \%$ & \\
\hline & $>20$ times & $2.6 \%$ & $9.7 \%$ & \\
\hline \multirow[t]{4}{*}{ Daily frequency of hand disinfection } & $<5$ times & $87.4 \%$ & $33.7 \%$ & \multirow[t]{4}{*}{0.001} \\
\hline & $5-10$ times & $9.1 \%$ & $36.7 \%$ & \\
\hline & 10-20 times & $2.2 \%$ & $20.6 \%$ & \\
\hline & $>20$ times & $1.4 \%$ & $9.1 \%$ & \\
\hline \multirow[t]{4}{*}{ Daily frequency of hand moisturizing (cream or Vaseline) } & $<5$ times & $61.0 \%$ & $41.1 \%$ & \multirow[t]{4}{*}{0.001} \\
\hline & $5-10$ times & $27.6 \%$ & $34.2 \%$ & \\
\hline & $10-20$ times & $8.9 \%$ & $17.2 \%$ & \\
\hline & $>20$ times & $2.4 \%$ & $7.4 \%$ & \\
\hline \multirow[t]{4}{*}{ Rubber glove use } & $<$ I per day & $24.6 \%$ & $12.5 \%$ & \multirow[t]{4}{*}{0.001} \\
\hline & $<$ I per week & $58.1 \%$ & $25.7 \%$ & \\
\hline & $3-4$ times per a week & $11.1 \%$ & $33.8 \%$ & \\
\hline & $>4$ times per a week & $6.3 \%$ & $28.0 \%$ & \\
\hline
\end{tabular}

Note: *p-value for McNemar's test.

Table 5 New-Onset Symptoms of Skin Damage Associated with Washing Hands and Using Disinfectants

\begin{tabular}{|c|c|c|c|c|c|}
\hline \multirow{2}{*}{\multicolumn{2}{|c|}{ Washing Hands and Using Disinfectants }} & \multicolumn{3}{|c|}{$\begin{array}{l}\text { After the Onset of the Pandemic, Have you Noticed Newly } \\
\text { Developed Obvious Skin Damage? N (\%) }\end{array}$} & \multirow{3}{*}{$\begin{array}{l}\text { Sig*. } \\
0.001\end{array}$} \\
\hline & & \multirow{2}{*}{$\begin{array}{l}\text { Yes } \\
\text { II (I2.8) }\end{array}$} & \multirow{2}{*}{$\begin{array}{l}\text { No } \\
115(21.9)\end{array}$} & \multirow{2}{*}{$\begin{array}{l}\text { I am not sure } \\
\text { II (22.0) }\end{array}$} & \\
\hline Daily frequency of handwashing with soap & Less than 5 & & & & \\
\hline & From 5 to 10 per day & $29(33.7)$ & $258(49.2)$ & $20(40.0)$ & \\
\hline & From II to 20 & $28(32.6)$ & $114(21.8)$ & $12(24.0)$ & \\
\hline & More than 20 & $18(20.9)$ & $37(7.1)$ & $7(14.0)$ & \\
\hline \multicolumn{2}{|l|}{ Total } & $86(100)$ & $524(100)$ & $50(100)$ & \\
\hline \multirow[t]{4}{*}{ Daily frequency of hand disinfection } & Less than 5 times & $22(25.6)$ & $189(36.1)$ & $15(30.0)$ & \multirow[t]{4}{*}{0.003} \\
\hline & $5-10$ times & $28(32.6)$ & $195(37.2)$ & $17(34.0)$ & \\
\hline & II-20 times & $20(23.3)$ & $109(20.8)$ & II (22.0) & \\
\hline & More than 20 times & $16(18.6)$ & $31(5.9)$ & $7(14.0)$ & \\
\hline \multicolumn{2}{|l|}{ Total } & $86(100)$ & $524(100)$ & $50(100)$ & \\
\hline
\end{tabular}

Note: *p-value for chi-square test. 


\section{Data Sharing Statement}

The data that support the findings of this study are available from the corresponding author, upon reasonable request.

\section{Ethics Approval and Informed Consent}

This study was approved by the IRB of Umm Al-Qura University in Makkah, Saudi Arabia (Approval No. HAPO-02-K-012-2020-10-451). All participants provided informed consent to complete the survey, and it was conducted in accordance with the Declaration of Helsinki.

\section{Consent for Publication}

No consent was taken from the participants since the report has been sufficiently anonymized and show no nominative information.

\section{Author Contributions}

All authors made substantial contributions to conception, design, acquisition of data, analysis and interpretation of data; took part in drafting the article or revising it critically for important intellectual content; agreed to submit to the current journal; gave final approval of the version to be published; and agree to be accountable for all aspects of the work.

\section{Funding}

The authors received no financial support for the research, authorship, and/or publication of this article.

\section{Disclosure}

The authors declare no conflicts of interest for this work and no potential conflicts of interest with respect to the research, authorship, and/or publication of this article.

\section{References}

1. Blicharz L, Czuwara J, Samochocki Z, et al. Hand eczema-A growing dermatological concern during the COVID -19 pandemic and possible treatments. Dermatol Ther. 2020;33(5). doi:10.1111/dth.13545

2. Water, sanitation, hygiene, and waste management for SARS-CoV-2, the virus that causes COVID-19. Available from: https://www.who.int/ publications/i/item/WHO-2019-nCoV-IPC-WASH-2020.4. Accessed January 26, 2021.
3. Guertler A, Moellhoff N, Schenck TL, et al. Onset of occupational hand eczema among healthcare workers during the SARS-CoV-2 pandemic: comparing a single surgical site with a COVID-19 intensive care unit. Contact Dermatitis. 2020;83(2):108-114. doi:10.1111/ cod. 13618

4. Lin P, Zhu S, Huang Y, et al. Adverse skin reactions among healthcare workers during the coronavirus disease 2019 outbreak: a survey in Wuhan and its surrounding regions. Br J Dermatol. 2020;183 (1):190-192. doi:10.1111/BJD.19089

5. Charan J, Biswas T. How to calculate sample size for different study designs in medical research? Indian J Psychol Med. 2013;35 (2):121-126. doi:10.4103/0253-7176.116232

6. Pattern of skin diseases in a hospital in Southwestern Saudi Arabia | request PDF. Available from: https://www.researchgate.net/publica tion/8620447_Pattern_of_skin_diseases_in_a_hospital_in_ Southwestern_Saudi_Arabia. Accessed May 4, 2021.

7. Visscher MO, Randall Wickett R. Hand hygiene compliance and irritant dermatitis: a juxtaposition of healthcare issues. Int $J$ Cosmet Sci. 2012;34(5):402-415. doi:10.1111/j.1468-2494.2012.00733.x

8. Rundle CW, Presley CL, Militello M, et al. Hand hygiene during COVID-19: recommendations from the American Contact Dermatitis Society. J Am Acad Dermatol. 2020;83(6):1730-1737. doi:10.1016/j. jaad.2020.07.057

9. $\mathrm{MOH}$ News. $\mathrm{MOH}$ Reports First Case of Coronavirus Infection. Available from: https://www.moh.gov.sa/en/Ministry/MediaCenter/ News/Pages/News-2020-03-02-002.aspx. Accessed May 6, 2021.

10. Cucinotta D, Vanelli M. WHO declares COVID-19 a pandemic. Acta Biomed. 2020;91(1):157-160. doi:10.23750/abm.v91i1.9397

11. Lan J, Song Z, Miao X, et al. Skin damage among health care workers managing coronavirus disease-2019. J Am Acad Dermatol. 2020;82(5):1215-1216. doi:10.1016/j.jaad.2020.03.014

12. Metin N, Turan C, Utlu Z. Changes in dermatological complaints among healthcare professionals during the COVID-19 outbreak in Turkey. Acta Dermatovenerologica Alpina, Pannonica Adriat. 2020;29(3):115-122. doi:10.15570/actaapa.2020.25

13. Johannisson A, Pontén A, Svensson Å. Prevalence, incidence and predictive factors for hand eczema in young adults - a follow-up study. BMC Dermatol. 2013;13:13. doi:10.1186/1471-5945-13-14

14. Al Shammrie F, Al Shammrie A. Pattern of skin disease in Hail region of Saudi Arabia. J Dermatology Dermatologic Surg. 2017;21 (2):62-65. doi:10.1016/j.jdds.2017.04.001

15. Borch L, Thorsteinsson K, Warner TC, et al. COVID-19 reopening causes high risk of irrit ant cont act dermat it is in children. Dan Med J. 2020;67(9):1-11.

16. Anveden I, Lidén C, Alderling M. Self-reported skin exposure-validation of questions by observation. Contact Dermatitis. 2006;55 (3). doi:10.1111/J.1600-0536.2006.00907.X

17. Guzek D, Skolmowska D, Głabska c D. Analysis of gender-dependent personal protective behaviors in a national sample: polish adolescents' covid-19 experience (place-19) study. Int J Environ Res Public Health. 2020;17(16):1-22. doi:10.3390/ijerph17165770

18. Breidablik HJ, Lysebo DE, Johannessen L, Skare JR, Kleiven O. Effects of hand disinfection with alcohol hand rub, ozonized water, or soap and water: time for reconsideration? J Hosp Infect. 2020;105 (2):213-215. doi:10.1016/j.jhin.2020.03.014 


\section{Publish your work in this journal}

Clinical, Cosmetic and Investigational Dermatology is an international, peer-reviewed, open access, online journal that focuses on the latest clinical and experimental research in all aspects of skin disease and cosmetic interventions. This journal is indexed on CAS.
The manuscript management system is completely online and includes a very quick and fair peer-review system, which is all easy to use. Visit http://www.dovepress.com/testimonials.php to read real quotes from published authors.

Submit your manuscript here: https://www.dovepress.com/clinical-cosmetic-and-investigational-dermatology-journal 